\title{
Innovative Method of Gas Control in Case of Accidents in Coal Mines
}

\author{
Oleg Tokarev ${ }^{1}$, Valery Popov², Anatoly Golik ${ }^{2}$, and Vera Zubareva ${ }^{3, *}$ \\ ${ }^{1}$ Kemerovo Region Administration, Department of Coal Industry, 65000063 Sovetsky av., \\ Kemerovo, Russian Federation \\ ${ }^{2}$ JSC NC VOSTNII, 6500023 Institutskaya st., Kemerovo, Russian Federation \\ ${ }^{3}$ T.F. Gorbachev Kuzbass State Technical University, 65000028 Vesennya st., Kemerovo, \\ Russian Federation
}

\begin{abstract}
In the article on the basis of the analysis it is proved that the currently used technical means and methods of control of the mine atmosphere in coal mines during the conduct of rescue operations it is impossible to obtain complete and timely information about the gas situation in the system of mine workings of the emergency site and adjacent potentially hazardous areas. The article describes an Autonomous small-sized multichannel gas control system of a new technical level, protected by a patent for a utility model developed by LLC "Research and production center for automation of safety" (Moscow) and a Branch of "Prokopevsky paramilitary mine rescue unit" FSUE "VGSCH" EMERCOM of Russia (Prokopyevsk) in order to eliminate the noted problem of monitoring the mine atmosphere in the liquidation of the accident.
\end{abstract}

\section{Introduction}

For more than a century and a half world experience in developing outburst coal seams, the cloud of scientific and technical ideas on solving issues of mining atmosphere control and preventing the spontaneous gas emissions in the bottomhole of the coal seam was accumulated. In the theoretical and practical terms, most of the fundamental tasks have been developed, substantiated and applied, such as a preliminary working out the protective mine seams (of the most efficient way); energy and energy-force theories of sudden coal and gas emissions have been developed and implied to a certain extent; the nature, causes and mechanism of sudden coal and gas emissions are substantiated in sufficient detail. All types of forecasting methane outburst zones (regional, local and current) have been developed and widely implemented. Locality in the manifestation of sudden emissions of coal and gas is practically confirmed: they are related to the zones of influence of geological disturbances, and, most importantly, to the time of technological impact on the bottomhole array of outburst-hazardous mine layers.

\footnotetext{
${ }^{*}$ Corresponding author: zubarevava@kuzstu.ru
} 


\section{Materials and Methods}

At the moment, in most of the operated coal mines there is a potentially explosive atmosphere. This is due to the presence of methane and suspended coal dust in combination with sources of ignition (electric sparks, heated bodies, sparks from friction, hot spots of spontaneous combustion of coal, etc.). In certain emergency situations caused by gasdynamic phenomena or violation of safety rules, an explosion with possible negative consequences is possible. It is known that the lower explosive limit of methane is $4.4 \%$, coal dust $-10-25 \mathrm{~g} / \mathrm{m}^{3}$ and depends on the dispersion (the most explosive dust consisting of particles 0.1-0.06 mm in size), volatile content, humidity and ash content. The presence of methane increases the degree of explosiveness of dust, for example, at $2 \% \mathrm{CH}_{4}$ the limit of explosive content of coal dust is reduced to $10 \mathrm{~g} / \mathrm{m}^{3}$, and at $3 \%-$ to $5 \mathrm{~g} / \mathrm{m}^{3}$ [1]. In connection with the increased explosion hazard of methane and dust air mixtures, the control over the content of methane and coal dust in the mine atmosphere is the primary task of air and gas control. In Soviet times, great attention was paid to the issues of controlling the composition and parameters of the mine atmosphere. Almost all coal mines, hazardous for gas and dust, were equipped with stationary and portable means of aerogas control [2]. Historically, research into the principles and methods underlying mining devices for controlling the mine atmosphere, developing their structures, bringing them to industrial production of the coal industry enterprises [3]. Many types of stationary equipment for controlling the mine atmosphere, which served as the basis for the creation of aerogas control systems, were developed, mastered by mass production and introduced.

However, today the innovative development of gas content monitoring in the mine atmosphere is going in the direction of increasing the accuracy of sensors and continuous monitoring in the event of accidents. There are two types of monitoring of the state of air in mines: scheduled and operational.

Planned control is carried out by sampling air in mine workings and subsequent analysis of these samples in the laboratory. The advantages of this type of control is that it can be used to determine the complete gas composition of the mine air. It provides high accuracy of determining the content of impurities in the air. The disadvantage is that a large amount of time (3-24 hours) passes from the moment of taking a sample to obtaining results. This makes planned control impossible to use during the accidents.

Operational control is performed by two types of instruments: automatic (continuous) and episodic instruments [4]. The positive side of the operational control is that there is practically no time interval between the moment of sampling and obtaining the result, which allows determining the content of harmful gases directly at the sampling site. But at the same time, each individual sampling with instruments for operational control allows determining the content of only one gas in the air, and with less accuracy than with laboratory analysis [5]. In case of an accident, the monitoring of the air condition in the mines is of an exclusively operational nature [6].

\section{Results and Discussion}

The mine rescue units (MRU) are working to eliminate the consequences of accidents occurring in coal mines in an extremely difficult and dangerous environment, which is further exacerbated by explosions and underground fires. The mine atmosphere is saturated with carbon oxide, carbon dioxide, methane, suspended coal dust, other poisonous and suffocating gases, becomes explosive and unsuitable for breathing. Under these conditions, the task of ensuring the systematic online receipt of adequate information on the gas composition of the atmosphere in the mine workings, which are potentially dangerous for the creation of emergency zones, comes to the fore. At the same time, there are often cases 
when the control points cannot be systematically accessed by people due to the presence of dangerous factors that create a constant threat to their lives. In such situations, gas monitoring should be carried out remotely.

Currently used in coal mines automatic gas control systems that allow to conduct it remotely, are intended only for operation in conditions of normal technological mode of operation of mines. In case of accidents, they are usually inoperable due to the failure of the interface, technical devices and equipment.

Remote gas control of the emergency site can also be carried out by sampling the mine air, followed by their laboratory analysis. Sampling is performed using a pre-created from a safe location to the control points of the plastic hose, which in a special container is pumped with pump gas mixture. Hoses are laid separately to each control point and represent separate branches which lengths depend on remoteness of places of a fence of the atmosphere and quite often reach several kilometers. In this regard, the mine air selected for laboratory analysis is supplied with a large time delay. At the same time, the probability of obtaining unreliable samples is not excluded. Due to the large length of the branches, there may be leaks at the joints of the hose, its damage during transportation and laying.

The described situations cause leakage into the hose of the outer atmosphere and, consequently, a change in the ratio of gas concentrations in the sucked mixture. This results in data that is completely inconsistent with their actual values. In addition, very significant time is required for the delivery of samples to the laboratory, the direct conduct of chemical analysis and the preparation of notifications to the heads of the liquidation of the accident on the results obtained. As a result, the headquarters for the management of the liquidation of the accident is supplied with essentially outdated and, consequently, incorrect information.

Thus, the currently used methods of monitoring the composition of the mine atmosphere in coal mines during the conduct of rescue operations can not receive complete and timely information about the gas situation in the system of mine workings of the emergency site and the surrounding potentially hazardous areas. Meanwhile, the receipt of late and/or unreliable data does not allow the timely adoption of the necessary measures in the current situation for the safe conduct of rescue operations and the prevention of complications during the liquidation of the consequences of the accident.

In connection with the problems described above, there is a need to develop an Autonomous multi-channel gas control system of a new technical level, the use of which will improve the tactics of emergency rescue operations, improve the safety of rescuers and take appropriate measures in a timely manner when there are factors that contribute to the complication of the situation in the process of eliminating the consequences of the accident.

Based on the joint research LLC "Scientific-production center of automation of safety" (JSC "SPC ATB", Moscow) and a Branch of "Prokopyevsk paramilitary mine rescue team of FGUP VGSCH" of EMERCOM of Russia (Prokopyevsk) developed small-sized multichannel system lamp control (MSGC) and allows for rapid deployment and monitoring of all gas streams that affect the composition of the mine atmosphere within the boundaries of the designated safe zone.

The system fully meets modern requirements for this kind of equipment and brings to a new level of safety of rescuers and underground workers of coal mines both in normal and in emergency situations. ICAC HAS no analogues and is protected by a patent for utility model No. 103135.

The system includes (Fig. 1) the following units and elements: unit of gathering information BSIP, block input/output sections of the interface YIPS485, unified unit source power WHIP, block emergency power BAP, sensors measuring the concentration of gases and atmospheric parameters of a series of ETS 2 different purposes, cables and communication lines connecting the blocks into a single system, a cable box (KK). 
CAC performs the following functions:

- continuous measurement of concentrations of controlled gases $(\mathrm{CH} 4, \mathrm{CO}, \mathrm{O} 2, \mathrm{H} 2)$, ambient temperature and atmospheric pressure in accordance with the types of connected sensors,

- recording of measurement results in real time,

- storage of fixed values of gas concentration, ambient temperature and atmospheric pressure with reference to the date and time of fixation,

- conversion of measured values to digital code,

- providing the possibility of transmission of recorded information through digital communication channels of stationary information systems, as well as through the IR-port to the Autonomous unit of removal and storage of information (ABSI),

- maintenance of long-term operation (up to 16 hours) from its own battery without the use of external power sources.

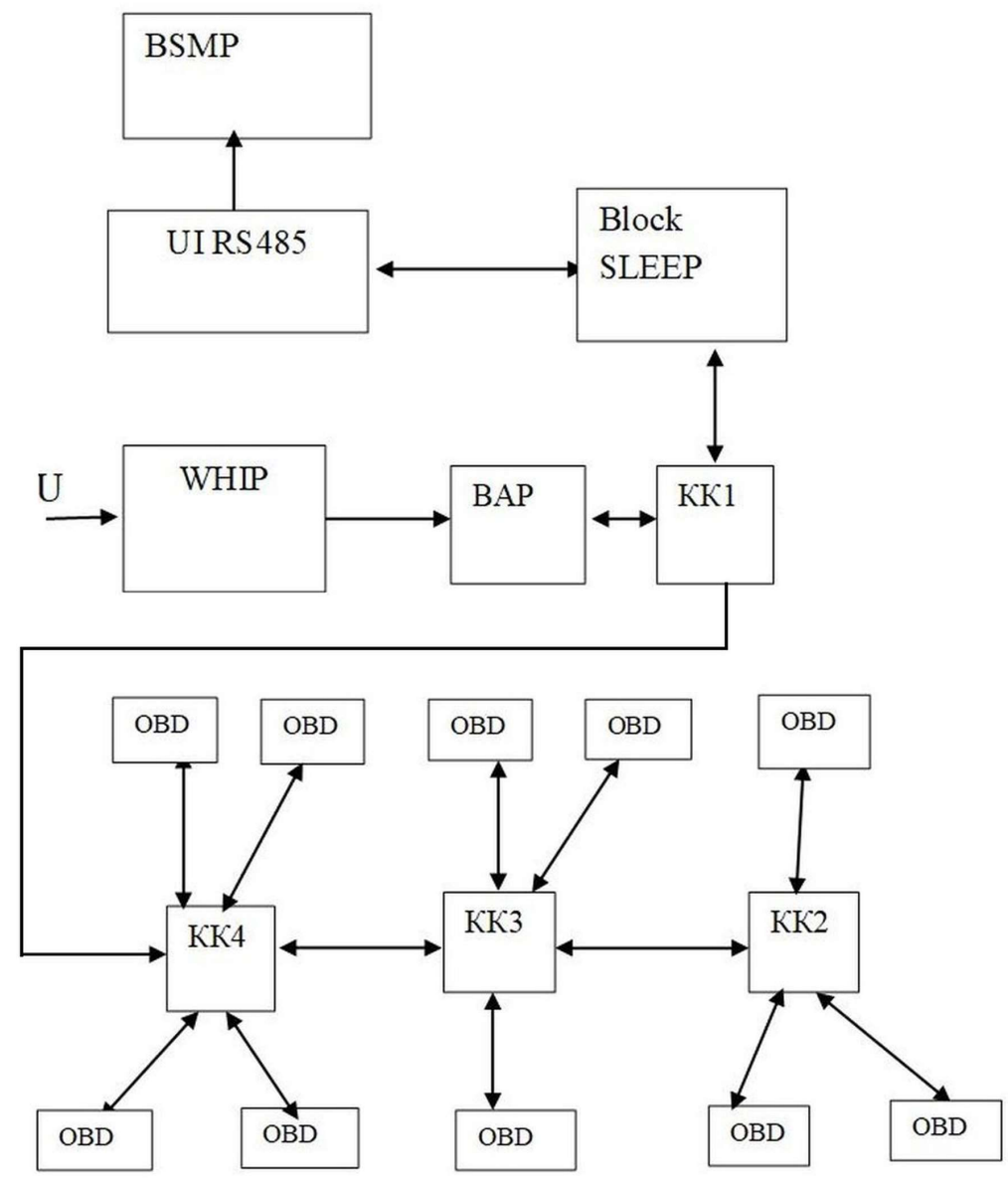

Fig. 1. The block diagram of the lamp control, MSAHC. 
Pilot tests of the system were carried out in the laboratory of SPC ATB LLC and at the Urgalskaya mine of Siberian coal energy company JSC (SUEK), positive results were obtained.

\section{Conclusion}

The information provided by MSAHC in the process of monitoring the composition of the atmosphere, in contrast to the currently used systems of remote gas control of emergency areas by mechanical sampling of mine air, allows not only to analyze the air and gas situation, but also to assess the mobility of temperature and gas fields in the network of mine workings. As a result, it becomes possible to predict the development of thermal and gas situations at the emergency site, and in the case of an unfavorable forecast to take preventive measures to ensure the safety of rescuers, to determine the time and place of safe access of MRU units to emergency facilities. Thus, the use of an Autonomous small-sized multi-channel gas control system brings to a new qualitative level the process of monitoring the mine atmosphere during the work to eliminate the consequences of accidents, increases the safety and efficiency of rescuers.

\section{References}

1. Federal regulations and rules in the field of industrial safety "Safety rules in coal mines" (RSTN, Moscow, 2014)

2. V. I. Burimov, V. B. Popov, The influence of gas on the thermal state of the rock mass (VOSTNII, Kemerovo, 1975)

3. A. S. Golik, Mine rescue business in Russia. Fuel and Energy resources of Kuzbass (VOSTNII, Kemerovo, 2001)

4. G. G. Sobolev, Rescuers, 2, 25 (1991)

5. V. B. Popov, Rescuers of Russia (VOSTNII, Kemerovo, 2004)

6. V. B. Popov, About aerodynamics of the developed space at working off of coal seam (VOSTNII, Kemerovo, 1990) 